\title{
IMPLEMENTATION ANALYSIS OF THE GUIDELINES FROM 2015
}

ANALIZA IMPLEMENTIRANOSTI PREPORUKA 2015

Zlatko Fišer ${ }^{1}$ Jelena Tijanić ${ }^{2}$, Mihaela Budimski ${ }^{3}$

\section{Sažetak}

Cilj

Analiza implementiranosti preporuka iz 2015. godine među lekarima, kroz tumačenje rezultata dobijenih u zadatom scenariju.

\section{Metodk}

U istraživanju je učestvovalo 250 lekara iz Srbije kojima je predočen scenario koji su samostalno trebali da reše u funkciji reanimacionog tima. Za analizu je korištena lista za ocenjivanje kvaliteta intervencije koju je sačinio Evropki resuscitacioni savet.

\section{Rezultati}

Prilikom primopredaje, i uvidom u monitoring, u visokom procentu se ne proverava podatak o srčanoj frekvenci i tenziji $(89,6 \%)$. Ne postoji posebno dizajniran tim za reanimaciju i kao takav se ne prepoznaje niti postoje treninzi koji se sprovodi za isti. Tokom sprovođenja reanimacionih postupaka ne postoji adekvatna oprema koji sadrži promptnu povratnu informaciju, prema preporukama 2015. Ne postoje ni uređaji koji beleže kvalitet rada i kvalitet primene mera CPR tokom sprovođenja dvo minutnog KPR-a. Ne postoji ni mogućnost evaluacije i provere kvaliteta rada pri vršenju mera resuscitacije. Tokom reanimacije kiseonik se češće upotrebljava u hospitalnim uslovima $(55,7 \%)$, nego što se primenjuje u prehospitalno $(22,3 \%)$. Praksa primene supraglotičnih sredstava je veoma niska kako na prehospitalnom $(16,5 \%)$ tako i na hospitalnom nivou $10,2 \%$ ). Monitoring pacijenta se vrši preko pacijent-kabela ili papučica defibrilatora. Prilikom davanja terapije, još uvek se koristi Atropin kod ritmova koji nisu šokabilni, češče u hospitalnim uslovima (31,2\%). Ne postoji mogućnost beleženja kvaliteta kompresija tokom KPR kao ni količine isporučenog vazduha. Ne postoji mogućnost minimiziranja perioda masaže jer se ne koriste samolepljive defibrilacione elektrode.

\section{Zaključalk}

Lekari u Srbiji nisu dovoljno upoznati sa protokolima iz 2015. godine te je nephodno implementiranje istog. Uvođenje standarda opreme i lekova u znatnome bi poboljšalo kvalitet sprovođenja i evaluacije postupaka resuscitacije.

\begin{abstract}
:
Aims

Implementation analysis of the guidelines from 2015 among physicians, through the interpretation of the results obtained in a given scenario.
\end{abstract}

\section{Method:}

The research included 250 physicians from Serbia who were introduced to the scenario they should have solved on their own as a part of resuscitation team. List for evaluating the quality of the intervention made by The European Resuscitation Council was used for the analysis.

\section{Results:}

During the handover and monitoring insight, the cardiac frequency and tension (89.6\%) was not checked in a high percentage. There is no specially established team for resuscitation and as such is not recognized nor there are any training that is carried out for that purpose. There is no adequate equipment containing prompt feedback, during the implementation of resuscitation techniques, as recommended from the 2015. There are no devices that record the quality of work and quality of implementation of measures during the implementation of two minutes CPR. Evaluating and checking the quality of the work in performing resuscitation measures, is not possible. During resuscitation, oxygen is often used in hospital conditions $(55.7 \%)$ than applied in the prehospital $(22.3 \%)$. The practice of applying supraglottic devices is very low, in both, the prehospital $(16.5 \%)$ and at the hospital level $(10.2 \%)$. Monitoring of the patient is performed through the patient cable or defibrillator paddles. When therapy is applied, there is still use of Atropine in nonshockable rhythm, more often in hospital conditions (31.2\%). It's not possible to note a quality of compression during CPR or the amount of a supplied air. Because there is no use of adhesive defibrillation electrodes, there is no option to minimize the period of compression.

\section{Conclusion:}

Physicians in Serbia are not sufficiently familiar with the protocols of 2015 and it is necessary to implement that protocols. Applying of the equipment and drugs standards would drastically improve quality of the implementation and evaluation in resuscitation procedure.

\section{USTANOUA}

Zavod za hitnu medicinsku pomoć Novi sad

ZZavod za hitnu medicinsku pomoć Kragujevac

${ }^{3}$ Služba za hitnu medicinsku pomoć, Dom zdravlja Subotica

\section{AUTOR ZA} KORESPODENCIJU: Zlatko Fišer

Resuscitacioni savet SCG tel +381628030640 www.resuscitatio.org.rs office@resuscitatio.org.rs

\section{KLUUČNE REČl:}

kardiopulmonalna reanimacija, protokoli 2010

10. oktobar 2015 DATUM PRIHUATANA RADA 20. oktobar 2015. DATUM OBJaVLJUANJA 10. decembar 2015. 
Tabela 1. Ocenjivačka lista

\section{INTERVENTIONS - KEY TREATMENT POINTS IN BOLD}

Cardiac arrest management

Confirm cardiac arrest
Call resuscitatin team / help
$2 \min$ CPR (30:2)

Airway / ventilation / oxygen

\section{Attach ECG monitoring}

Give adrenaline $1 \mathrm{mg}$ IV

Recognise and treat relevant reversible causes (hypoxia - intubation; hypovolaemia - IV fluids)

Check monitor / confirm rhythm

1st shock at appropriate energy

2 min CPR (continuous chest compression / ventilation)

Minimise interruptions in CPR

Check monitor / confirm rhythm

Give further IV adrenaline every 3-5 min

Minimise interruptions in CPR

2nd shock at appropriate energy

2 min CPR (continuous chest compression / ventilation)

Check monitor / confirm rhythm

Check patient (signs of life / pulse)

Post resuscitation care najčešči propusti

Ne postojanje podatka o tenziji i srčanoj frekvenci kada je prvi ritam PEA ili VT

Ne postojanje posebno dizajniranog tima za reanimaciju, Ne postoji definisan trening tog tima

Ne postojanje opreme koja koristi PROMTNU POVRATNU INFORMACIJU - definisanu Preporukama 2010

Ne postojanje uređaja koji beleže kvalitet rada i kvalitet primene mera CPR

Ne postoji mogućnost evaluacije i provere kvalieta rada pri vršenju mera resuscitacije)

Ne postoje podaci o učestalosti primene kiseonika u toku CPR posebno u vanbolnickim uslovima i protoku, duzini primene i sl.

Ne posatoje podaci o učestalosti primene supraglotičkih sredstava

(preporuke dozvoljavaju prekid od 5 sekundi) prime-

na Endotrahelane intubacie traje od 30sec do 1 minuta

- ovaj prekid rada smanjuje uspešnost mera reanimacije za 5 do 10\%. /10\% po minuti prekida CPR i odlaganje DC šoka/

Ne postoje adhezivne elektrode za defibrilaciju te se monitorig vrši preko pacijent kabela ili papučica defibrilatora.

Još uvek se u ritmovima Električna aktivnost bez pulsa i Asistolija primenjuje ATROPIN

Ne postoji praksa korišćenja supraglotičkih sredstava u resuscitaciji

Ne postoje pouzdani podaci o isporučenoj količini energije tokom resuscitacije kao indikator kvaliteta rada u ustanovi, uređaji ne koriste memorijske kartice sa beleženjem načina njihove upotrebe.

Ne postoji mogućnost beleženja kvaliteta kompresija tokom CPR i količine isporučenog vazduha

Ne postoji mogućnost minimiziranja perioda masaže jer se ne koriste samolepljive defibrilacione elektrode

Ne postoji mogućnost minimiziranja perioda masaže jer se ne koriste samolepive defibrilacione elektrode

Ne postoje pouzdani podaci o isporučenoj količini energije tokom resuscitacije kao indikator kvaliteta rada u ustanovi

Ne postoji mogućnost beleženja kvaliteta kompresija tokom CPR i količine isporučenog vazduha

Ne postoji standardizovana procedura postresuscitacione nege koja uključuje i terapeutsku hipotermiju, čime se ne radi dovoljno na prevenciji ostećenja mozga te je samim time konačni ishod mera resuscitacije kompromitovan 
Tabela 2. Implementacija protokola 2015-analiza scenarija.

\begin{tabular}{|lccc} 
& ukupan broj učesnika & hospitalni & vanhospitalni \\
\hline $\mathrm{n}(\%)$ & 250 & $147(58,8 \%)$ & $103(41,2 \%)$ \\
\hline ritam spojiv sa životom (provera pulsa i tenzije) & $9(3,6 \%)$ & $5(3,4 \%)$ & $4(3,8 \%)$ \\
\hline postojanje tima za resuscitaciju & & anestezija & HMP \\
\hline oprema za merenje kvaliteta rada CPR & 0 & 0 & 0 \\
\hline samolepljive elektrode & 0 & 0 & 0 \\
\hline upotreba supraglotična sredstva & $41(16,4 \%)$ & $15(10,2 \%)$ & $26(25 \%)$ \\
\hline upotreba kiseonika & $105(42 \%)$ & $82(55,7 \%)$ & $23(22 \%)$ \\
\hline upotreba lekova: Atropin & $54(21,6 \%)$ & $46(31,2 \%)$ & 8 \\
\hline sprovođenje postresusc.hipotermije & $7(2,8 \%)$ & $5(7,35)$ & $2(2 \%)$
\end{tabular}

\section{Uvod}

Smernice za reanimaciju Europskog saveta za reanimaciju (ERC) 2015. godine objavljene su 18.10.2015. godine na web stranicama ERC-a. Kao i prethodni vodiči, i ovaj 2015. bazira se na najnovijem Internacionalnom KPR konsensusu sa preporukama za lečenje (International Consensus on CPR Science with Treatment Recommendations- CoSTR), koje objedinjuju rezultate sistematskih preglednih članaka na razne teme vezane za KPR. Resuscitaciona nauka nastavlja da napreduje. Klinički vodiči se moraju redovno ažurirati kako bi reflektovali ovaj napredak i izvestili zdravstvene radnike o najboljem načinu rada. Tokom petogodišnjeg ažuriranja vodiča, naučne tvrdnje mogu pružiti zdravstvenim radnicima informacije o novim terapijskim metodama koje mogu značajno uticati na ishod zbrinjavanja kritično obolelog pacijenta.

\section{Cilj}

Analiza implementiranosti preporuka iz 2015. godine među lekarima, kroz tumačenje rezultata dobijenih u zadatom scenariju.

Metod rada: $U$ istraživanju je učestvovalo 250 lekara iz Srbije kojima je predočen scenario koji su samostalno trebali da reše u funkciji reanimacionog tima. Za analizu je korištena lista za ocenjivanje kvaliteta intervencije koju je sačinio Evropki resuscitacioni savet.

\section{Rezultati}

U istraživanju je učestvovalo 250 lekara širom Srbije. Od toga je $144(57,2 \%)$ zasposleno hospitalno, dok je 103 lekara $(41,2 \%)$ sa prehospitalnog nivoa. Svi lekari su dobili identičan scenario koji su trebali samostalno da reše. Scenario je podrazumevao pacijenta koji se nalazi u sobi za intervencije, žali se na bol u grudima, dok sestra snima EKG, odjednom gubi svest i prestaje disati, sestra poziva lekara, tim za reanimaciju i počinje mere spoljašnje masaže srca i veštač- kog disanja, očekujući da tim za reanimaciju pristigne. Lekar, učesnik u istraživanju je "reanimacioni tim" koji preuzima pacijenta. Na monitoru, pri primopredaji pacijenta, je ritam spojiv sa životom ali bez pulsa. Lista ocenjivanja kvaliteta intervencija obuhvatala je 19 parametara. Najčešći zapaženi propusti su dati u komentaru u ocenjivačkoj listi (tabela 1). Prilikom primopredaje, i uvidom u monitoring, u visokom procentu se ne proverava podatak o srčanoj frekvenci i tenziji $(89,6 \%)$. Ne postoji posebno dizajniran tim za reanimaciju i kao takav se ne prepoznaje niti postoje treninzi koji se sprovodi za isti. Tokom sprovođenja reanimacionih postupaka ne postoji adekvatna oprema koji sadrži promptnu povratnu informaciju, prema preporukama 2015. Ne postoje ni uređaji koji beleže kvalitet rada i kvalitet primene mera CPR tokom sprovođenja dvo minutnog KPR-a. Ne postoji ni mogućnost evaluacije i provere kvaliteta rada pri vršenju mera resuscitacije. Tokom reanimacije kiseonik se češće upotrebljava u hospitalnim uslovima $(55,7 \%)$, nego što se primenjuje u prehospitalno (22,3\%). Praksa primene supraglotičnih sredstava je veoma niska kako na prehospitalnom (25\%) tako i na hospitalnom nivou 10,2\%). Monitoring pacijenta se vrši preko pacijent-kabela ili papučica defibrilatora. Prilikom davanja terapije, još uvek se koristi Atropin kod ritmova koji nisu šokabilni, češće u hospitalnim uslovima (31,2\%), tabela 2. U daljem toku postupaka reanimacije ne postoje podaci o količini isporučene energije tokom resuscitacije kao indikator kvaliteta rada jer se u ustanovama u kojima rade lekari ne koriste memorijske kartice sa beleženjem načina njihove upotrebe. Iz istog razloga ne postoji mogućnost beleženja kvaliteta kompresija tokom KPR kao ni količine isporučenog vazduha. Ne postoji mogućnost minimiziranja perioda masaže jer se ne koriste samolepljive defibrilacione elektrode. Po završetku reanimacije, koja je po scenariju uspešna, ne postoji standardizovana procedura postresuscitacione 
UDC 615.816/.817(497.11)"2015"

616.12-008.315-085(497.11)"2015"

nege koja uključuje i terapeutsku hipotermiju. Zbog ne standardne opreme ne radi se dovoljno na prevenciji oštećenja mozga te je samim time konačni ishod mera resuscitacije kompromitovan.

\section{Diskusija:}

Studije na različiti način opisuju proveru implementacije protokola u razvijenim zemljama. U Danskoj je sprovedeno istraživanje o teoretskom znanju novih smernica putem maila (3). Više istraživanja ukazuju, ukazuje da upotreba uređaja sa povratnom informacijom, znatno poboljšava procenu rada kardiopulmonalne resuscitacije odn. merenja kvaliteta kompresija grudnog koša i isporučene ventilacije $(4,5)$. Autor rada Robert M.Sutton ukazuje da kvalitet usluga koje se pružaju tokom postupaka resuscitacije ne zadovoljavaju standarde opreme koje su zasnovane smernicama (6). U našoj zemlji ne postoje propisani standardi za resuscitaciju koji bi bilo vodiči za implementaciju protokola. Ustanove koje su akreditovane imaju utvrđene protokole ali ne i standarde koji je prilagođen istim. Resuscitacioni svet Velike Britanije, ima propisane standarde opreme i lekova koji se primenjuju u kardiopulmonalnoj resuscitaciji za zdravstvene ustanove. Pored ovih, propisan je način edukacije, formiranja timova i lidera, neophodnih kurseva, retreninga kao i vođenja administracijeo iznenadnom srčanom zastoju (7).

\section{Zakıjučak}

Lekari u Srbiji nisu dovoljno upoznati sa protokolima iz 2015. godine te je nephodno implementiranje istog. Uvođenje standarda opreme i lekova u znatnome bi poboljšalo kvalitet sprovođenja i evaluacije postupaka resuscitacije.

\section{Reference:}

1. Hazinski MF, Nolan JP, Aickin R, Bhanji F, Part 1: Executive Summary: 2015 International Consensus on Cardiopulmonary Resuscitation and Emergency Cardiovascular Care Science With Treatment Recommendations. 1. Circulation. 2015 Oct 20;132(16 Suppl 1):S2-39. doi: 10.1161/ CIR.0000000000000270.

2. Secher N, Mikkelsen MM, Adelborg K, et al. Direct mail improves knowledge of basic life support guidelines in general practice: a randomised study. Scand J Trauma Resusc Emerg Med. 2012 Oct 14;20:72. doi: 10.1186/1757-7241-20-72.

3. Sainio M, Tenhunen J, Olkkola K, Hoppu S. Implementation of resuscitation guidelines 2010 has little effect on survival in a tertiary referral hospital. Resuscitation: 83 (2012) e24-e123.

4. Brennan EE, McGraw RC, Brooks SC. Accuracy of instructor assessment of chest compression quality during simulated resuscitation. CJEM. 2016 Jul; 18(4):276-82. doi: 10.1017/cem.2015.104. Epub 2016 Jan 18.

5. Robert M. Sutton R, Nadkarni V, Benjamin S. Abella. "Putting It All Together" to Improve Resuscitation Quality. Emerg Med Clin North Am. 2012 Feb; 30(1): 105-122. Published online 2011 Oct 15. doi: 10.1016/j.emc.2011.09.001

6. Resuscitation Council UK 2014 - 2017. Available from: https://www.resus.org.uk/quality-standards/primary-care-quality-standards-for-cpr/ 